

\title{
Histórias do Ensino do Desenho
}

\author{
Ana Mae Barbosa
}

The Notebooks of Leonardo da Vinci, ${ }^{1}$ copilados e editados dos manuscritos originais por Jean Paul Richter são evidências cabais de que para Leonardo o desenho era fundamental em todas as suas múltiplas atividades.

Contudo nos dias atuais há um desinteresse enorme por pesquisas que esclareçam a importância do desenho para profissionais projetistas, para o cotidiano das pessoas, para - desenvolvimento da cognição e na educação para as Artes, para o Design, para a Arquitetura.

Até mesmo o desenho da criança tão estudado até a década de 80 tem sido esquecido. De Luquet (1913) ${ }^{2}$ a Claire Golumb $(1992)^{3}$ muita pesquisa confiável foi produzida sobre a evolução do desenho livre da criança, mas o que se escreve e se vende hoje são meras receitas para aprender a desenhar, entre elas o livro Drawing on the Right Side of the Brain Workbook (1998) ${ }^{4}$. Os exercícios que Betty Edwards propõe neste livro produzem bons resultados por serem desinibidores da expressão, mas cientificamente nenhuma pesquisa demonstrou que realmente ativam o lado direito do cérebro.

\footnotetext{
1 The Notebooks of Leonardo da Vinci compiled and edited from the original manuscripts by Jean Paul Richter New York: Dover Publications, 1970.

2 LUQUET, Georges-Henri. Les dessins d'un enfant (Children's Drawings). Paris, Librairie Félix Alcan, 1913.

${ }^{3}$ GOLOMB, Claire. The Child's creation of a Pictorial World. Berkeley, Los Angeles, Oxford. University of California Press, 1992, 353 pgs.

${ }^{4}$ EDWARDS, Betty. Drawing on the Right Side of the Brain Workbook, 1998, Penguin Putnam.
}

DOI : $10.5965 / 24471267522019130$

http://dx.doi.org/10.5965/24471267522019130 


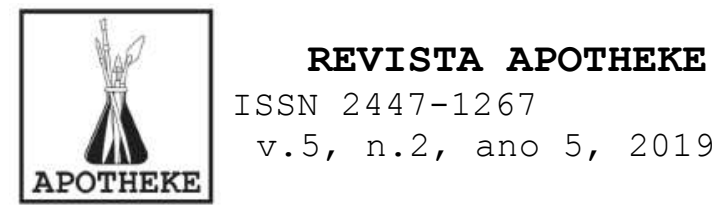

No fim do século XIX os mais eficientes defensores do Desenho no Brasil foram Ruy Barbosa e André Rebouças, ambos políticos e o último prestigiado engenheiro e professor. Minha imaginação utópica fica inventando como teria crescido o ensino do Desenho no Brasil se estes dois tivessem se aliado. Entretanto com a República Ruy Barbosa circula no epicentro do poder e André Rebouças vai para o exílio. Primeiro foi para a França, mas as dificuldades econômicas o levaram para Moçambique. Ando com enorme nostalgia acerca daqueles que lutam pelo Brasil e depois são rejeitados, por isso estou lendo os diários de Rebouças, leitura que recomendo para os dias de hoje, não tão diferentes dos de então.

Não resisto em citar uma passagem destes diários:

Barbeton - Grande Hotel, 15 de Novembro de 1892. Meus queridos Taunay ${ }^{5}$ e Nabuco. Considerando Vocês meus testamenteiros morais e intelectuais, enviolhes, neste tristíssimo aniversário, o seguinte Índice dos meus trabalhos desde 15 de Novembro de 1889 até 15 de Novembro de 1892, nos três anos mais extraordinários da minha vida. (...) Atribuo ao Bom Deus, a meu santo Pai e ao exemplo vivo do meu Sublime Mestre e Imperador a divina inspiração de partir do Brasil a 17 de Novembro 1889, no Alagoas, com a Família Imperial. Desde então, a cada telegrama da minha miséria Pátria, exclamo: - Que horror! Que seria de mim se lá estivesse?!... (...) Um hediondo escravocrata disse a Taunay ter ficado muito contente "porque a Princesa Redentora chorou a valer". Este canibal e outros celerados que reduziram o Brasil ao horror atual, devem estar também muito contentes de estar André Rebouças na Costa d'África" e, há 3 anos sem receber do Tesouro Nacional... - Perdoai-lhes, meu Santo Pai... Não têm consciência do que estão fazendo... São maus por estúpidos, são estúpidos por excesso de maldade. "(REBOUÇAS, André, 1938) ${ }^{6}$

\footnotetext{
5 Trata-se de Alfredo D'Escragnolle Taunay, Visconde de Taunay e Joaquim Nabuco que como Carlos Gomes eram seus melhores amigos.

6 REBOUÇAS, André. Diário e Notas Autobiográficas. Coleção Documentos Brasileiros dirigida por Gilberto Freyre, Livraria José Olympio Editora, Rio, pág. 395 a 397, 1938.
} 


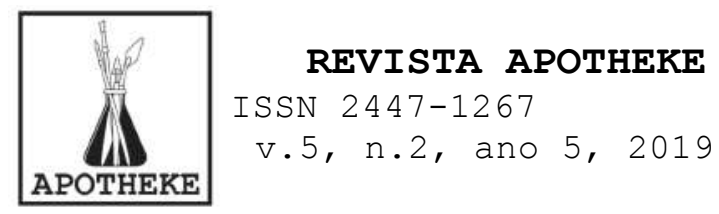

André Rebouças como tinha 35 anos de serviço público não pode ser demitido mas foi aposentado à revelia. Depois de muita luta começaram a pagar sua aposentadoria que trocada por moeda inglesa valia 7 libras no fim de sua vida.

Enfim o destino de Rebouças me comove, lutou tanto pela liberdade dos escravos no Brasil, sendo ele próprio negro, mas dez anos depois, aos 58 anos, solitário cheio de dívidas que se preocupava em pagar, doente e sem dinheiro para sobreviver cometeu suicídio atirando-se ao mar em frente ao hotel onde por último morou em Lisboa (1898). Até o fim da vida desenhou, na África e em Portugal exemplares da flora local o Desenho que defendeu como aprendizagem essencial quando era jovem pensando no desenvolvimento do país tornou-se seu consolo.

Os projetos educacionais de Ruy Barbosa nunca foram implementados integralmente mas alguns exercícios práticos de desenho são usados até hoje nos guias curriculares do Brasil, como a rede estimográfica, processo de ampliação de figuras pela reprodução aumentada em trama quadriculada. 7

Só em três momentos da história oficial do sistema de ensino da Arte no Brasil foi dada a mesma importância ao Desenho e/ou Artes Visuais que as outras disciplinas.

1. Nos projetos de Reforma do Ensino Primário e no Projeto do Ensino Secundário e Superior de Ruy Barbosa ${ }^{8}$

2. Reforma Fernando de Azevedo ${ }^{9}$

\footnotetext{
7 Ver dissertação de Mestrado de MILANEZ, Carolina Gonçalves. Ensino da Arte e do Design em uma escola municipal de São Paulo. Universidade Anhembi Morumbi, Programa de Arte. Design e Tecnologia, 2016 e BARBOSA, Ana Mae. Arte-Educação no Brasil: das origens ao modernismo. São Paulo: Editora Perspectiva, 1978 .

8 BARBOSA, Rui. A reforma do ensino secundário e superior (1882). Rio de Janeiro, Ministro Ministério da Educação e Saúde, 1941; Id. Reforma do ensino. Primário, 1883. Apud BARBOSA, Ana Mae. Arte-Educação no Brasil: das origens ao modernismo. São Paulo: Editora Perspectiva, 1978.
} 




3. Reorientação curricular da Secretaria Municipal de Educação quando Paulo Freire e Mario Sergio Cortella foram secretários.

Entretanto ao longo da sua história o Desenho no Brasil sempre teve defensores esparsos.

Já nos primeiros anos da abertura política depois da ditadura do Estado Novo (37-45) os educadores aproveitando a abertura para experimentação pedagógica dada pelo Governo Federal recomeçaram a campanha em favor do Desenho nas escolas embora fragmentada

Um dos textos bastante lido na época da experimentação na educação dos anos 50 foi a tese de catedrática da artista Georgina de Albuquerque intitulada. O Desenho como base do Ensino das Artes Plásticas apresentada em 1942 na Escola Nacional de Belas Artes onde era professora Ela foi a primeira mulher a dirigir aquela escola e era sufragista, isto é defendia o direito de voto para as mulheres de todas as classes sociais. Georgina Albuquerque tinha muito prestígio no seu tempo e somava ao seu próprio prestígio o prestígio do marido Lucilio de Albuquerque (1887-1939) a quem dedica a tese escrita depois da morte dele. Ser casada, amante ou filha de homem importante sempre foi uma faca de dois gumes para as mulheres pois possibilita que os antifeministas as respeitem hipocritamente em público no momento de sua ascensão mas as desqualifiquem em privado e ao longo do tempo dizendo que só são consideradas por terem associação com um homem importante. Não sei se por esta razão ou se foi o machismo determinante da história mas Georgina ficou esquecida por quase meio século.

9 BARBOSA, Ana Mae. Redesenhando o desenho: educadores, política e história. São Paulo: Editora Cortez, 2015. 


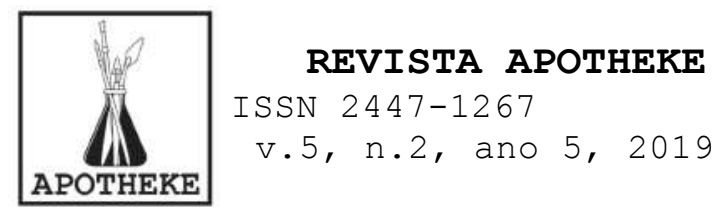

Me enche de alegria ver que o movimento feminista vem recuperando sua trajetória e sua presença em exposições o que é muito relevante por ter sido ela própria uma feminista da primeira onda. Mulheres de hoje, ao se aliarem ao feminismo vocês estão lutando contra o apagamento de mulheres pela História e contra o seu próprio apagamento.

Uma exposição em Santiago do Chile intitulada "Yo soy mi propia musa. Pintoras latinoamericanas de entreguerras (19191939)", 17 de abril a 30 de junho no Museo Nacional de Bellas Artes inclui obra de Georgina de Albuquerque junto as brasileiras Tarsila do Amaral (1886-1979), Lucy Citti Ferreira (1911-2008), Noemia Mourão (1912-1992) y Anita Malfatti (1889$1964)$.

Destas mulheres artistas brasileiras Anita e Tarsila ${ }^{10}$ são muito comemoradas hoje mas estiveram no ostracismo na década de 40 de onde foram resgatadas por mulheres pesquisadoras da Arte respectivamente Aracy Amaral e Marta Rossetti que escreveram sobre elas. Este é um exemplo claro de que mulheres precisam escrever sobre mulheres se queremos reescrever a História da Arte sob uma perspectiva democrática, iqualitária. Lucy Citti Ferreira foi simbolicamente enterrada aos pés do comemorado Lasar Segall sendo considerada apenas sua modelo e musa pela crítica.

Sempre houve muita dificuldade em enquadrar a produção das mulheres nos ismos historicamente determinados. Frida Kahlo e Grete Stern foram consideradas surrealistas e Georgina impressionista, quando foram apenas mulheres que tinham consciência de serem mulheres. Georgina tinha orgulho de ter trabalhado todos os dias de sua vida até mesmo quando os

10 A exposição de Tarsila Popular no MASP que se encerrou dia 28 de julho de 2019 foi visitada por 402.000 visitantes, o maior número de visitantes de uma exposição no Brasil. 


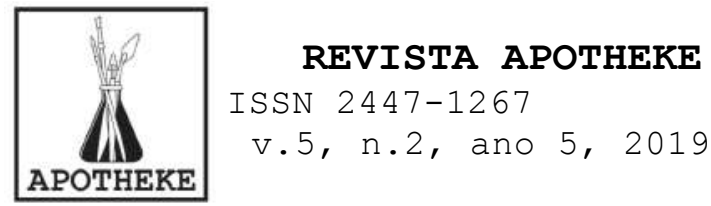

filhos Dante e Flamingo eram pequenos. Foi a primeira mulher a fazer uma pintura histórica Até hoje este gênero é negado às mulheres Um exemplo da proibição disfarçada é a desconsideração pela magnifica pintura de Teresa Costa Rego representando a Guerra dos Guararapes. A obra histórica de Georgina intitulada Sessão do Conselho de Estado de 1922 comemora a Independência e pertence ao Museu Histórico Nacional do Rio de Janeiro.

O site do MAR onde esteve recentemente exposta a obra comenta:

Na obra Sessão do Conselho de Estado, Georgina de Albuquerque apresentará em 1922 a primeira pintura de gênero histórico, uma obra em grandes dimensões feita por uma artista brasileira. Trata-se também da primeira tela que confere à Imperatriz Leopoldina seu papel ativo como estadista no exato momento em que assume posição favorável à Independência do Brasil junto a José Bonifácio, Clemente Pereira, Martim Francisco, Gonçalves Ledo e outros civis- alguns dos quais vestem a farda verde usada após a Independência pela alta patente do exército imperial brasileiro sugerindo o triunfo da escolha política decorrente do momento encenado. A obra com características impressionistas e temática própria do formalismo academicista em voga foi realizada para participar do concurso da Exposição do Centenário da Independência que previa a realização de uma mostra sobre as principais modalidades de trabalho. Para o evento foram produzidas duas pinturas que realçaram a participação da Imperatriz Leopoldina na história nacional: a de Georgina de Albuquerque que encontra-se hoje em exposição permanente no Museu Histórico Nacional e a tela de Domenico Failutti Retrato de Dona Leopoldina de Habsburgo e seus filhos (1921), exibida no núcleo Dona Leopoldina e sua descendência desta exposição. ${ }^{11}$

Como feminista Georgina nesta obra não só afirma a participação política da Imperatriz Leopoldina na Independência do Brasil como destaca sua participação no gesto em direção a ela de José Bonifácio, homem a quem se atribuiu sozinho por algum tempo a redação da primeira constituição

11 https://www.museudeartedorio.org.br/en/node/3969, consultado dia 31/07/2019. 


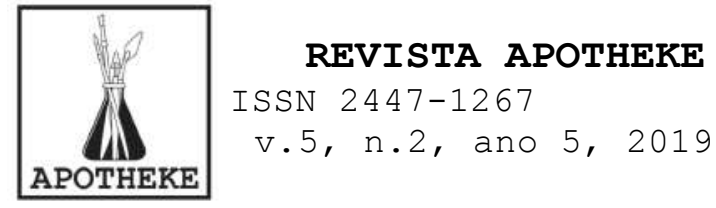

brasileira. Hoje sabe-se que ela muito contribuiu para a escrita da Constituição e para o reconhecimento da Independência do Brasil pelas potencias estrangeiras. É verdade que teve de pagar a aprovação da nossa Independência a seu país de origem, a Áustria, criando assim mais uma dívida externa para o Brasil além da que já "tínhamos" com Portugal. Se a História oficial destaca José Bonifácio que tem um monumento em praça pública com sua figura austera em New York atrás da Biblioteca Pública na Quinta Avenida entre as ruas 42 e 43, Leopoldina tem a maior homenagem que o povo brasileiro pode prestar a alguém, é referenciada em segunda instancia pela Escola de Samba a famosa Imperatriz Leopoldinense criada em 1959. O nome da Escola é em homenagem a Estrada de Ferro Leopoldina, que atravessava o bairro de Ramos onde está baseada hoje a Escola que por sua vez foi assim designada em homenagem direta à Imperatriz Leopoldina. Logo o titulo da Escola é homenagem, indireta à Imperatriz. Sem querer, por acaso se fez justiça histórica. 


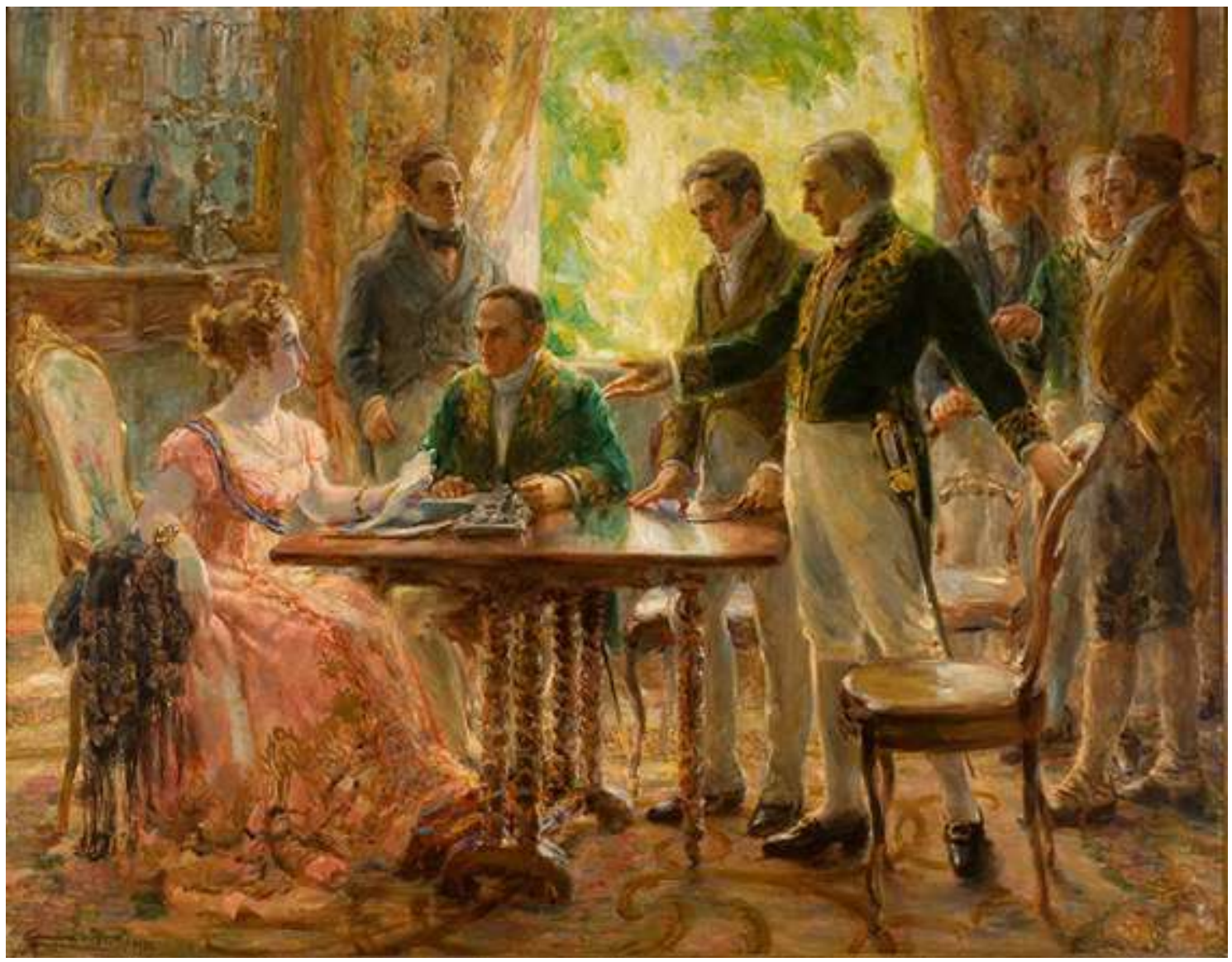

Figura 1: Sessão do Conselho de Estado, Georgina de Albuquerque. Fonte: https://www.museudeartedorio.org.br/en/node/3969, consultado dia 31/07/2019

Observem o contínuo gestual dos braços e mãos dos dois personagens principais, a Imperatriz Leopoldina que segura os documentos chegados de Portugal exigindo o retorno de Pedro I à Portugal e o de José Bonifácio que aponta para a Imperatriz . Os gestos quase interligados revelam a maior importância dos dois na Independência A intensa luz que se vê ao fundo que interpreto como alusão ao futuro do país que naquela cena se delineia foi, dada à má vontade de um crítico da época, interpretada como incompetência para trabalhar o fundo Afinal - crítico era um homem julgando uma mulher ousada em seu ofício.

As considerações sobre o ensino do Desenho de Georgina de Albuquerque são válidas até agora. 


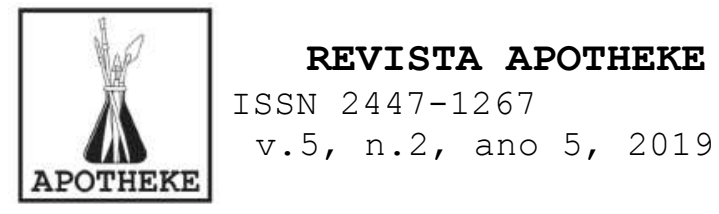

Entretanto suas sugestões práticas são convencionais mesmo para o seu tempo e inadequadas para hoje. Necessitamos agora em tempos depois do pós-modernismo de um sistema de ensino do Desenho que inter-relacione o desenho digital e o desenho manual pois este último continua sendo essencial para o desenvolvimento da percepção visual e da capacidade de traduzir em duas dimensões 0 mundo tridimensional. Este processo cerebral e não só visual é importante até para o desenvolvimento da flexibilidade como qualidade e processo envolvido na criatividade.

O desenho digital é também essencial especialmente na Arquitetura, Design Gráfico, Design de Produtos pois é mais preciso e mais homogeneizador como pede a industrialização. A dissertação de mestrado de Maximilian de Aguiar Vartuli ${ }^{12}$ considera que:

Muitos profissionais conservaram sua demanda por ferramentas de desenho que reproduzam características artesanais ou manuais, semelhantes às da manipulação de materiais e técnicas artísticas tradicionais, sendo notória a utilização de processos tradicionais de desenho em fases iniciais de um projeto, tais como a confecção de esboços ou sketches para a visualização de ideias e conceitos.Será que estes profissionais não são os melhores? São exemplos extraordinários os desenhos dos arquitetos Oscar Niemayer e Abrão Sanovicz ${ }^{13}$

Desculpem, mas não escrevo mais artigos acadêmicos, somente ensaios com todo respeito à academia e não às suas normas quase esterilizantes.

Meu objetivo é dedicar os anos de pesquisa que me restam a difundir a produção e as ideias de mulheres deixadas do lado do fora da HISTÓRIA.

Por isso, coloco à disposição dos leitores a tese de Georgina de Albuquerque para que possam degustar e exercer a

12 VARTULI, MAximilian de Aguiar. O design do desenho: análise de ferramentas de desenho digital no projeto de produto. Mestrado Acadêmico em Design UDESC /CEART, 2016 pag 24.

13 SANOVICZ, Fernanda. Desenhos de Abrahão Sanovicz, São Paulo: SESC, 2016 


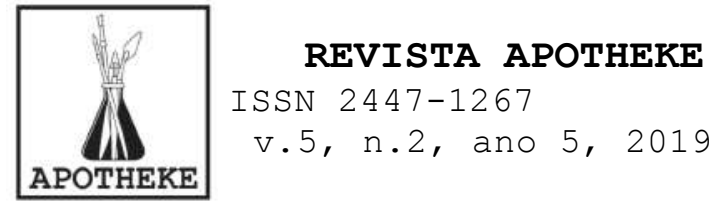

capacidade crítica acerca do passado, comparando-o com o presente.

Foi para mim uma emoção encontrar esta tese com o papel quase a se desfazer no início dos anos 70 na magnifica Biblioteca da EBA. Uma cópia dela ficou perdida em meus arquivos.

Procurei-a inutilmente para dar notícia dela no livro Mulheres não devem ficar em silencio: Arte, Design e Educação. São Paulo: Editora Cortez, 2019. Escrevi então à Biblioteca da EBA e a bibliotecária muito generosamente me enviou esta cópia já digitalizada, que estou compartilhando com vocês. 
POR

OEOROIHA DE ALBUQUBRQB

Ti tulsds pela Bscola ae

Belas Artes de Paris en 1910

Livre docente de pintura de Bacola Nactonal de Belas Artes por ooncurso de provas em 1927. Bx professora contrateda Aa esde1ra paralela de pintura da Zscola Hacional de Belas Artes em-1934. Bxx professors o chefe de sessão do curso de arte decorativa do Universidnde do Distrito Federal (1935) Profeseoro interina da cadeira de Pintura de Becola Neoionel de Belaa Artes (1987) Professora interina ca cadeira ora ell concurso, da mesma Iscola (1939) Con 8 (oito) anos de professorado neste meama Bacola. Orande medalha de prata (1909); pequene mednitha de ouro (1912) o grande medalha de ouro (1919) nos Salöes Nac1onaes do Belas Artes - primelro grande premio no Balăo Argentino (1937) Quadros nos Museus de Belas Artes, Historico, Munio1pal e de Arte Decorativa do R1o de Janeiro, Pinscotéca de São Paulo, Museus da Bafa, Reclfe, Buonos Aires e Anerica do Norte. Quadros em d1versas importantes galemas partioulares. 

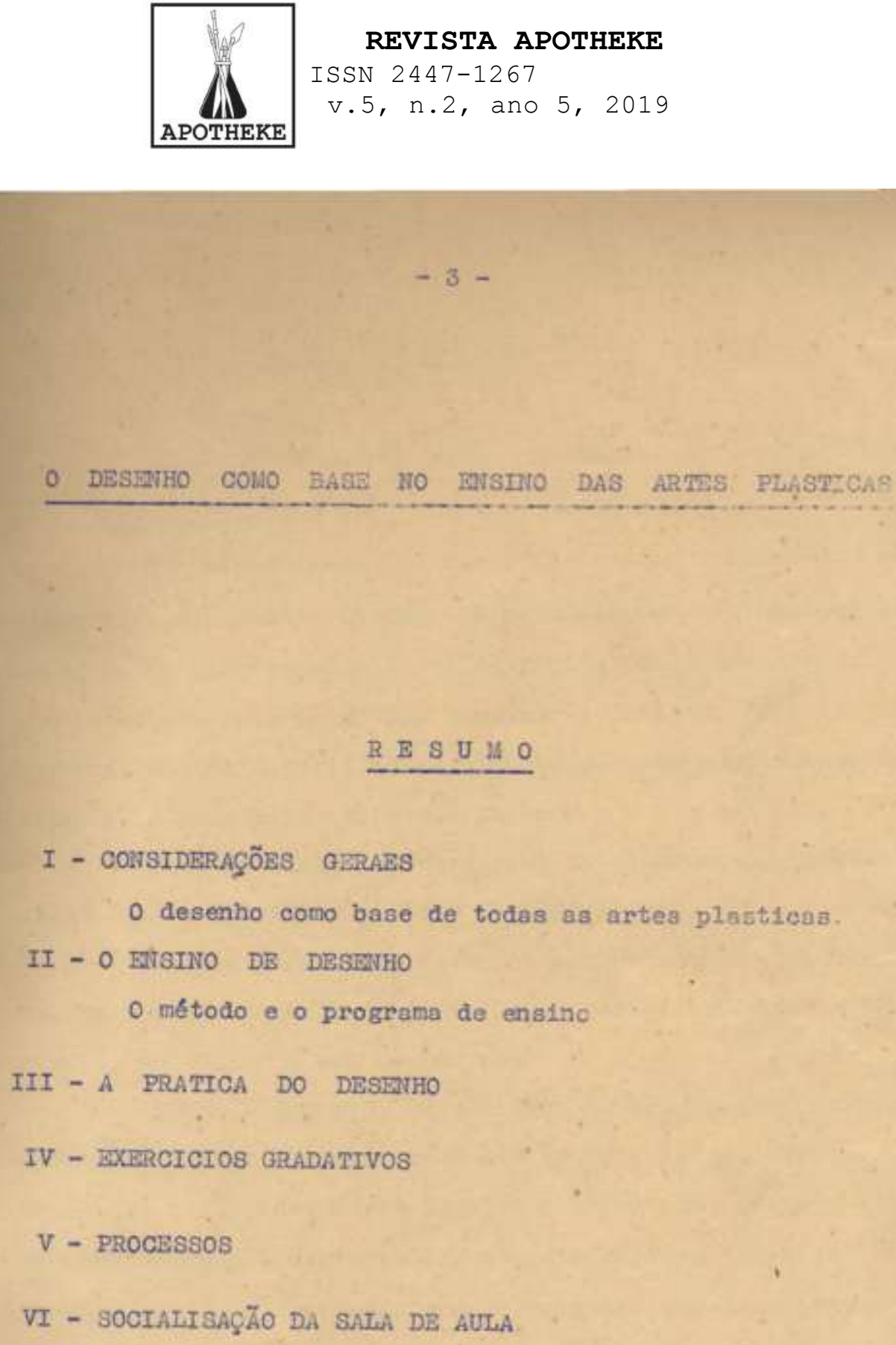


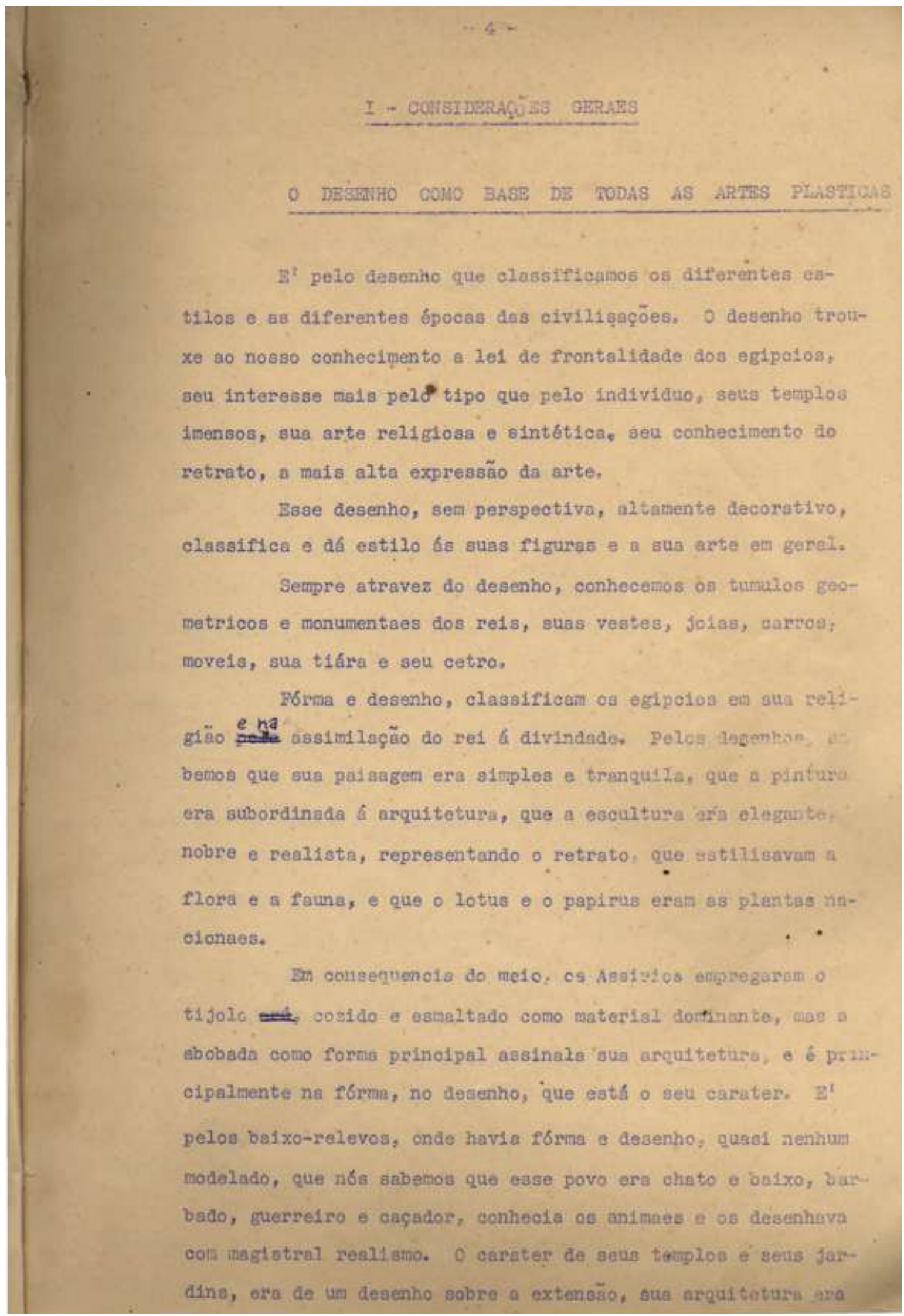




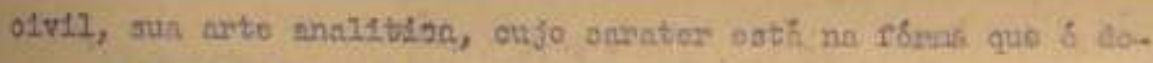
aonho, do tal manolre gue podexomos traças un touro alado do For-

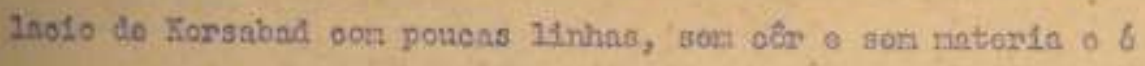

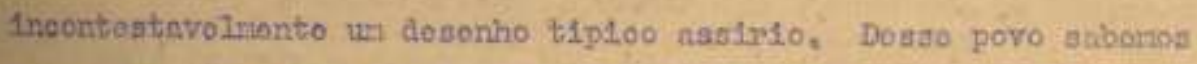
polos dosonhos dos baloco-rolovas oono so banquotenva, como oxar wous utonasicios.

0 mundo do hojo possuo intaotas aiguma pogas din mato groga o mutan ma1s ou monos mitilades, alassiffcadas dietintes dus do primolro perlodo da arto onogowronana polo dosonho quo ats diatinguo o oaraotoxias, nosan ooisa difloilina da arto groga quo 8 a bolose forral, son outra procuró quo a hrwionsa das fromas, o quo. podonos quasi dizor quo a belesa para os Crogos ora uma expresshio matonatioa con modulo o omon. Por maion difforonça que soja A de ratoria prina osprogade 6 o dosoniso quo distinguo a axto gregs da nute ogipola o da romann,

Bubora nos prinolvos torpos do Bom os intsetas tonhas stdo grogos, o fausto do Rona lovou os antistas $\delta$ um dosoTho th1s oorplloado do ffman o vomos a suporpostgäo das oxdons, - robuseado da folthn do aeanto o o orpprogo do nroo. Iato $b$, form mn oonsoquonto da matoris omprogadn, O dosenho guo timhis diforonoluto a Groolin arouloa da Grooln to Phidins, diforonola agora orit Roma ns oxpressobes ans figuras dn bolose forme para fis do oxm prossbos do pasxt̃o.

Arabos o Porsns tivorar a sua forran o o sou dofiorho

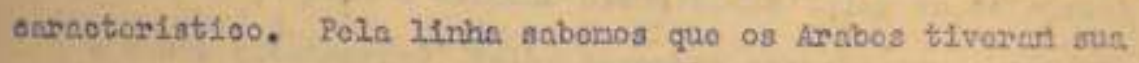

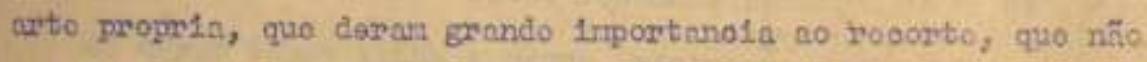
modolavas o quo orar ongonhosos e roquintados; dornor mals que rooothoratr the arto dos outros povos.

Bt afrda a floma do wr dosonho mala fino, quo distinguto ume poluma porsa oora sou ospltol do touro alndo o exa beaso do Cosorho t5̃o dolloado.

Mnda polos 1 iwatnuras dos mamusorstos Rorass, polo dosonho do sous tapetos magristaos, do anua miroos broonitos, do. 


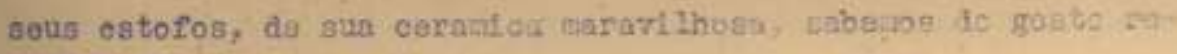
quintado a'esse poyo.

A China of Japăo, spesar dis Itnhas gue te assonethati. pelo desenho podemos distinguir o valor de suns artes a diforenoial-as.

Vomos fia Paleatine nos balxo-relevos de tnmulos, um deaenho naturalista a dellcado, inspirado na folhs da ollvelra, no eacho de uva, no carvalho, etc; suas vestes eram male ol mples que as dos povos anteriores e não representavam 11 guras na decoraģăo.

Quando na ́́poca medieval a estatuaria quasi desaparoce para maior impulso ao azulejo, ao esmalte a f́ joalheria, nĭo é ab a materia que muds, mas o desenho e o coratér da 1inih

Nos livros de oraçōes (o maís celesore é o Kanuai pan selino), no ambiente dos mostelros, a escrite $\delta$ derenhads e o desenho $\&$ a escrita dos artistas biasntinos. ' $]^{\prime}$ a fórria, o dovenho, que, com o s1stems arquitetonico difevenciom as cabedraes romanices das goticas e cada uma d'elas entre sf. B' o desomho, a linha e a arquitetura da Idade Ledia, qus ansaterisain a forro do Palac1o Publico do S1enna, ou a muralha do Palacio Qs Avigmó.

Dessa Ǵpoca notamos o rebuscado da forma da'rlors na đecoraçäo que 8 de un desenho realiota e minuoloso, mas de mels requintado gosto de apl1cação.

Forras e desenho classificam todris as catedraes goticoe e a aua estatuaria. Pelos desenhos sabetio que o th rerro forfađo dessa ́́poca tinhs a mesma inspiração decorativa de anquitetura O3 Papas Julio II e Leon X, Adriani VI. Clemente VII e Paulo III moroam 0 apogeu de arte da fráun. Z é principulmonte pela forma, 1sto 6 , pelo desenho, que classiflcanos o desenho magostoso de Miguel Angelo, o desenho espiritual de Lecnardo of tenenho aentimental de Rafael.

$E^{\prime}$ atravez do desenho que distinguimos todos oz grandos ertiatea do renascimento, a orqustetura e o mobiliarlo. o. 


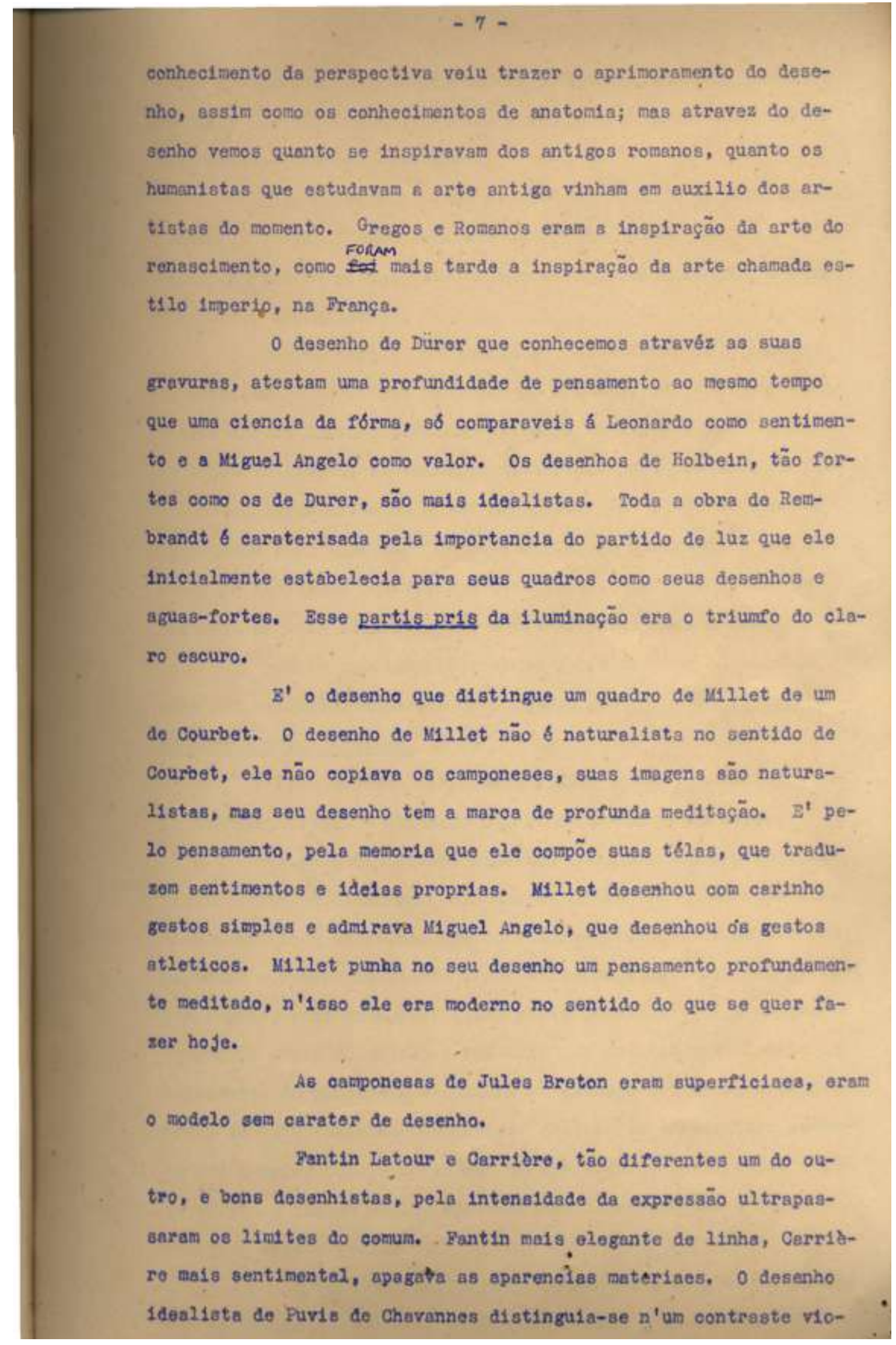


poder de penetração, que fol necessario para o coptar e a força de Inaginaçäo que pernitilu de o reproduzir com tel relevo qua exalts nossa admiração.

A exatidão o a propriedade dos traços não tomam velor estético senäo porque testenunhan da ap11caçäo do artista, de sua consciencla, aua penetração, sua enoção e seu pocer de traduz1r sua 1topresaäo.

A 1 in tação đa natureza não $\delta$ senĩo o me1o, ou antea a ocasiäo e o pretexto. A verdadelra e unios fonte da arte 60 proprio artista. Uma obra de arte para ser classificada na categorla das obras expressivas, 6 condíf̧ão trazer a marca de una imbginaçāo e de uma sensibilidade que ultrapassem o nivel comum. o primelro culdado do ensino deve ser pois, de despertar as personalidades.

Reclama-se que a Bscola (1) é arcaica, mas, no ensino escolar, não são propriamente as regras, os preceltos geralmente procedentes da experiencla e de uma juata observação, que toThen um tento o desenvolyimento da mocldade, $\delta$ antes a falta de mot1vo e de ocasião de expandir o ólan, o movimento, o cazor das almas juveris.

O que faz falta $\mathbb{B}$ Becola of o culdado de elevar o nivel de oul tura e de gosto, não por mais uma aula de estét1ca por exomplo, mas por series de conferenclas, exposições e entretiens 1lustrativos como 11 çöes de bom gosto e oultura plastica e tecnica, e como alimento espiritual ás faculdades artisticas 1natea dos alunos. N' $N^{t}$ esses pesquisas constantes, consagradas 808 Jovena com Intençäo de os desenvolver, de os gular sobre os oampos da emoģăo estética, solio1tando a expergaäo de sua capacidado intelectual 6 que consti tue a verdadeira fonte da arte. Afinando sua sensibilidade os levariamos a vibrai e expandir-a mals livres, mala pessoaes o mals expontaneos. Esse desenvolvitiento, verdađelras aulas prealcas de gosto o cultura artiation teriam ainda (1) Rer1 rome a Essoola no sentido do enaino olaseico. 


\section{$-10-$}

outra vantagem, a de đespertar em cada um, um exame de suas proprias aptidöes. Se o astudo ce reduz 6 coptas a 1mitaçöes, repet1çōes do que flzeram os outros, todos poden fazer o mesmo, mas so o estudo do arte fôr a revelação de une personal1dade, s1 flcar bem claro que para ser artista ó preciso ter inaginação, ter sensibilidade, entusiamo, aptidëo instintiva, dominante de traduzir sob forma plastica suas emoçōes, haveria mals revelaçōes de verdadeiras vocaçōes, mais esclarecimento e mals senso pratico, evitando desperdielos de termo para aqueles on que outras aptidōes podem ser melhor aproveitadas en outros ramos de ativicede. 
A cadolra do doochho en vorourao. eongts do cumplouIun do 18 Are do Chrego de Pintura, Bscultura a Gravura, e está clasalfioado como cadelina pratica,

Com a minha experiencia de muttos anos do ensino, condidero que serta mus to mals ut11 que a cadelre de desenho constasas do 18 e 28 Aro do curriculur e fosae teoricompratica, Poderua-1a objetar que os alunos tâm đesde 18 , ats o uItimo ano, desenho de modelo vivo, mas todos sabemos que năo 6 poselvel dar qunlquer 11 ção teorica quando o modeio está etu pose.

Bssa alula comporta: oв alunou en trabalho, aproveitando o modelo e o professor corm gindo individualmente.

Nas aulab de desenho, onde o modelo 6 eatatico, $b_{\text {mul- }}$ to diferente. Ai deven ser dadas no quadro negro qlgunes explicagões necessarias atravéz de graficos do professor, sobre o mecanismo an V1são, as Jels de perspectiva, planos, sombra propria e projetada, anatomia, etc., cujas aulas esceciaes do ourso, reg1đas por notavela professores, os aluncs nâo sabem coordenar por o1 mesmo, para aplicar go desenho. Sô quando o professor desetha $\theta$ explica no qundro negro 6 que o alumo reallza que os conheolrentos que esta adquirindo nas dema1s materiss do curriculum, šo meios pars aprenđer desenho, assir oomo desenho ó meio para sprender as artes plasticas. Bsse metodo teoricompratico é tanto mals necessario quanto temos agora anexo ao ourso de P1ntura, - curso de formaçäo do Profossorea Secundarios do Desenho.

\section{DESBNHO}

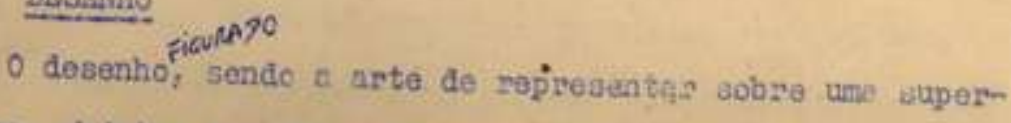
flolo plana, objetor que tân na renlidade tres dimonaöes, sltura, largura e profundadade, tomanse neseasario pasa, aprender a desenhar, duas cousas indispensavefs: 
D. PRATHCA.

\section{O. MEMODO DE ENSTIOO}

0 metodo de ensino compreende:

18 - As caracteristicas do ensino do desenho

82 - OB prellminarea

3R - O sent1do do desenho

48 - 0 eapirito do programa.

19 - AS CARACTERISTICAS DO BMSTNO DO DESEMHO

As ceracteristices baseam-se nos diferentes tipos de exposição đo ensino atravez dos quaes 6 obtida a metodologia do ensino do desenho. o objetivo das 11 çōea didaticas aobre đesenho \& trazer uma contribuiçäo metodologica baseada sobre experienclas pedagogioas. Caracterise o ensino o desenvolvimento das faculdades de observaçäo e anal1ae, que á Justamme.o que distingue o desenho do adulto do desenho da criança, o adulto vê, observa, copla, pensa, sente, Inventa e póde ser original, a criança apenas vê e sente. A cobservação $\&$ a anallse das fómas, 0 conhecimento do objéto ou reunião de objétos, 6 a viaão de conJunto das fómas 11 gadas entre a1 por velaçōes intradependentes. - que se completam umas nas outras. Pelo metodo se estabelece que faz-se um desenho com uma construgão, partindo dos al1cerces so confunto, e do conjunto ao detalhe, estabelecendo pontos de referencia babeados na pergpectiva de observaçäo.

\section{8 - OS PRHLTMINARES}

Como preliminapes para uma bôa anal1se đas fơmes, säo necessarios conhecimentos do mecanlomo da visão, cone V1aual, eto, conhecimentos de perspectiva, porque 6 imposaivel desenhar justo una forma qualquer, Bein fazer wales et memes porspectiva. Por 1sso, Leonardo Da Vino1 vie na perspeotiva a razäo universal do desenho. 
* Sendo a perapectiva a ciemola dae fórmas aparented $s$ ritster, para representer os objetos taes quaes parecer, conheceles, taes quees são. Una förma que se desenhasse sem compreenđot, Eeria dific1l fazer compreender aos ctrtros.

Nos preitininarea eatí colmpreendida a orjentagăo de como aproveitar no desenho figurado, os conheoinentos adquiridos nas cadeiras de peropectiva nodelagen e anatomia.

\section{2 - Q SBXITDO DO DRSTMUO}

Apreender o sentido do desenho $\hat{f}$ chegur á observaçäo subt11, f́ auto-critica sincera, de como foras obtidas os relevos, atravéz do traço e da luz e sombra. $z^{\prime}$ o desenvolvimento da sensibilidade, realizando o que ven a'ser acordenaçäo, entre o que Be observa e o que te executa. $\mathbb{Z}^{\prime}$ conhecer mentalmente, atravéz das dificuldades progresoivas os resultados das maneiras aiferentes de execuçäo. $z^{\prime}$, enfin, o conheosmento do đesenho atravéz da propria experiencia.

\section{R. = O BSPIRTIO DO EROGRAMA}

0 esplrito do programa estú na coordenngrio los perlohon gradativos de materia estudads, que constituen o treino metodisado para a rinalidede do ourco.

O programa póde ser empirico e a orientaçäo cas aulas Ber livre, tudo degende da interpretaçšo do professor, So a exiguidade de tempo toine 0 desenvolvimento.

Ha alumos que disentem problenas complicadiasinos de geometria, entratanto derenhen errados o pedestal do busto a a coluna em que pousa o modelo; para eles perspectiva 6 una cousa, desenhar 6 outwa, chegam ao f1m do ano sem realtoar que estudam (y perapectiva para ter conheoimento do horizonte e dac nstas para lelas fugindo pare um ponto de fuga na linha do horizonte. Os alunos astuder projeçöes, plmos e, quando se eneontram diante do modelo, floam atragnihados dorn o selevo e clevo excuro dos al- 

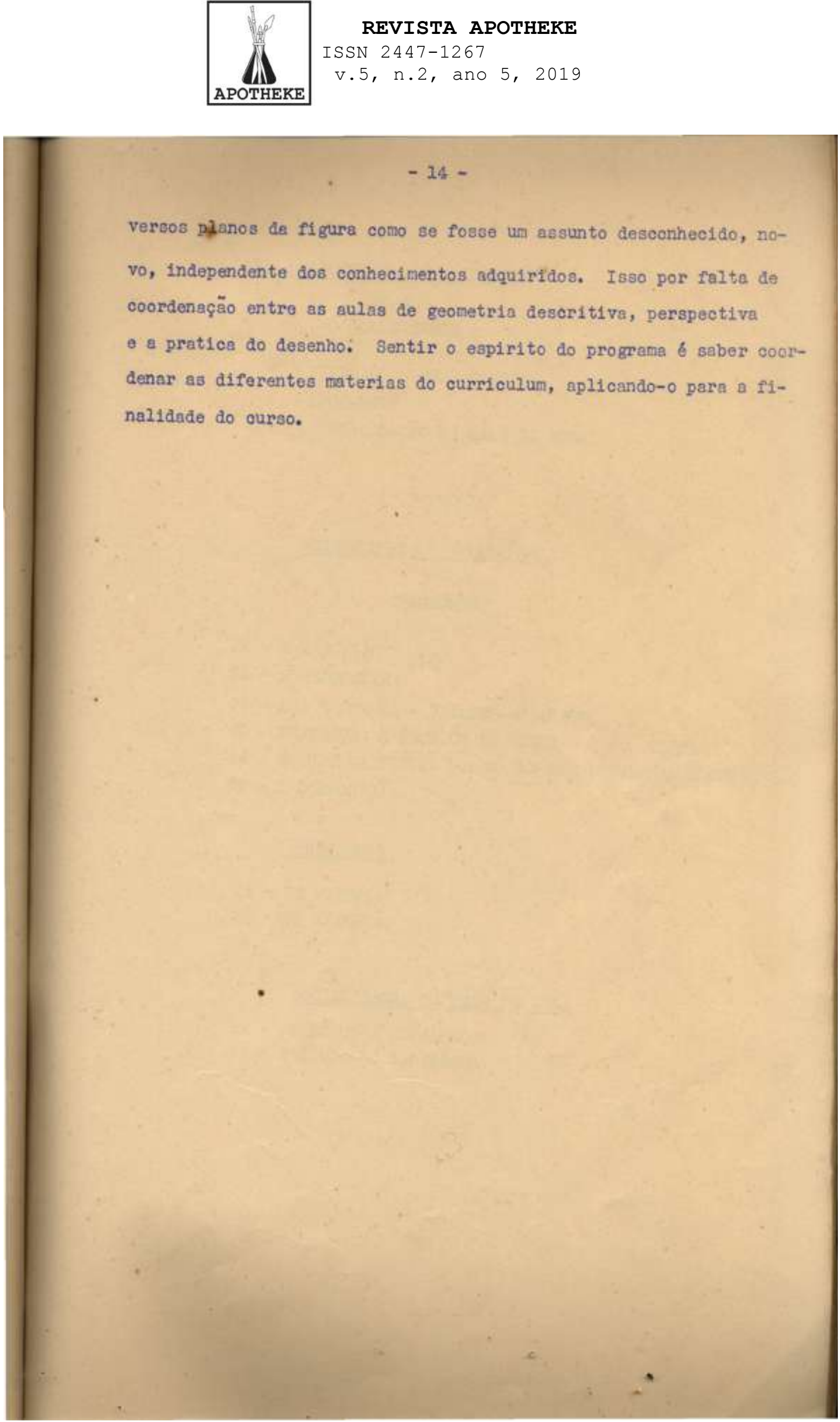


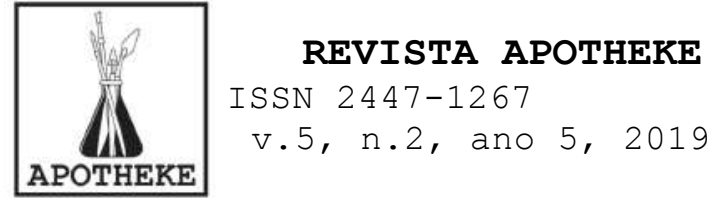

$$
-15-
$$

III - PRATICA DO DEBENHO

COMPREERDE :

BXERCICIOS GRADATIVOS

PROCESSOS

SOCIALISAÇÄO DA SALA DE AULA

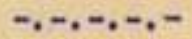

EXIRCICIOS

GRADATIVOS

COMPRBINDE :

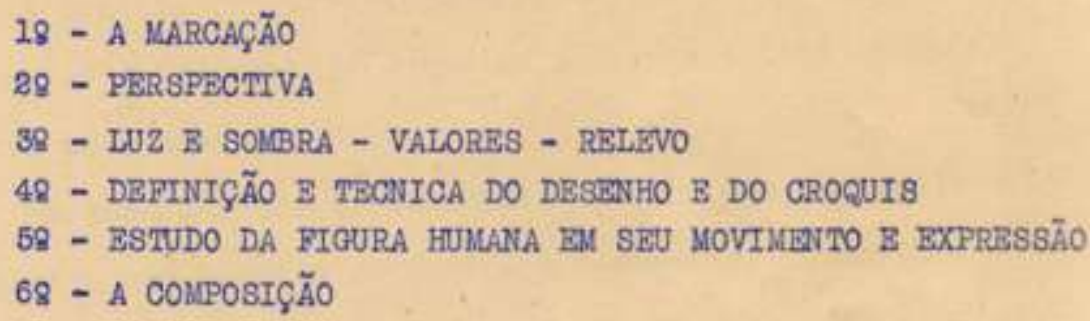

PROCESSOS

18 - DE MATBRIAL

2Q - DE EXECUÇÃO

\section{SOCIALISACÄO DA SALA DE AUHAA}

18 - PSICOLOGIA DO ALUNO

38 - ATITUDE DO PROFESSOR 
Cono aplicaçāo do metodo, a pratica representa, o treino s1mul taneo da v1 são e da execução, olho e mão tenđo função 1gual. Como todo estudo, o desenho requer do estudante uma at1tude de interesse.

Para aquísição dessa atitude de interesee (opiniăo, modo de vâr e de fazer, conhecimento etc.) é indispensavel que 0 professor demonstre a utilidade e os objetivos do estudo e das experienclas sucessivas que comporta o metodo de engino em particular e do ourso em geral.

A pratica comporte a maneira de ver e comparar, estabelecendo pontos de referencia entre as partes $\theta$ o todo do modelo, o a mane1ra de executar.

Etm cada unidade de treino deve haver ume idela diretriz que nunca deve ser perdida de viata, é a Esreuruea do estudo.

En desenho acadenico a flgura humana forme a principal unidade de treino, a formula 1deis. Todo o estudo gira en tomo da figura quer com modelos de gesso, quer com modelo vivo.

Na cadeira em concurso, todos os processos e exerololos para conhecimento de conjunto, generalidade ou relatividade para concelto de volume, relevo e detelhes, Bäo feitos atravéz de modelos en gesso, reproduçäo do clessico.

para o curso de pintura 6 tambem interessante estuder desenho atravéz de objétos de materia e côres diferentes, desenvolvendo conheolmento de técnicas e aplicaçäo das lels de contrastes e reflexos, etc. Atravf́z de obj6tos de materia e ooloraçōo diferentes, \& que se p6dem fazer estudos de polioromia em claro escuro que vem a ser a base para os EFeiros da perspectiva aerea em pinture.

0 desenho 6 como um Jogo, ten regras para chogar 6 sun Innalldade, 0 desenho pbde aer mesmo encarado como uma clenoia no sentido de que obedece \& leis fixas imutaveîs. 0 artiate näo 
póde fugir dessas regras.

Alem deasas regras que provêm de lels de perapectiva, Luz, eto, ha ainda o treino da teenica em s1, que deve seguir um determinado andamento e que tem tamben as suas regras.

\section{REQRAS QUE AUXTLTAM A PRATICA}

1 - Tomar conheoimento do modelo para depois iniolar o desenho.

$z$ - Comparar e medir vertical e horizontalmente até ter perfelta ideí da at1 tude a das proporções das massas en geral.

3 - Batabelecer uma medida quo alrva de módulo para essas comparações.

4 - Desenhar construindo e chegar ás sombras pela pesquisa da forma.

$\sqrt{5}$ - Proceder sempre de conjunto ao detalhe, de manelra a poder parar an qualquer momento, dando o desenho a Justa 1mpressão de estar sendo felto com inteligenola e conhecimento.

6 - Rnoarar as tres fázes do desenho: 18 - des bases construtıvas, 38 - da construção em andamento, 38 da construção em acabamento.

7 - Observar muitas vezes antes de traçar.

8 - Cu1dar da fresoura do papel para poder obter traços dellcados e sombras transparentes.

9 - Comparar o desenho com o modelo, colocando um ao lado do outro.

10 - Näo convem conversar enquento $3 e$ desenha, porque olhos, măo e mente trabalham juntos. Isso 6 ind1spensavel ao ritmo. Quando um falte, falha o outro.

11 - Nĕo riscar com forçe.

12 - Näo cobrir ó papel com sotribras escuras.

13 - Näo traçar na superfioie as sorbras que vem da pro- 


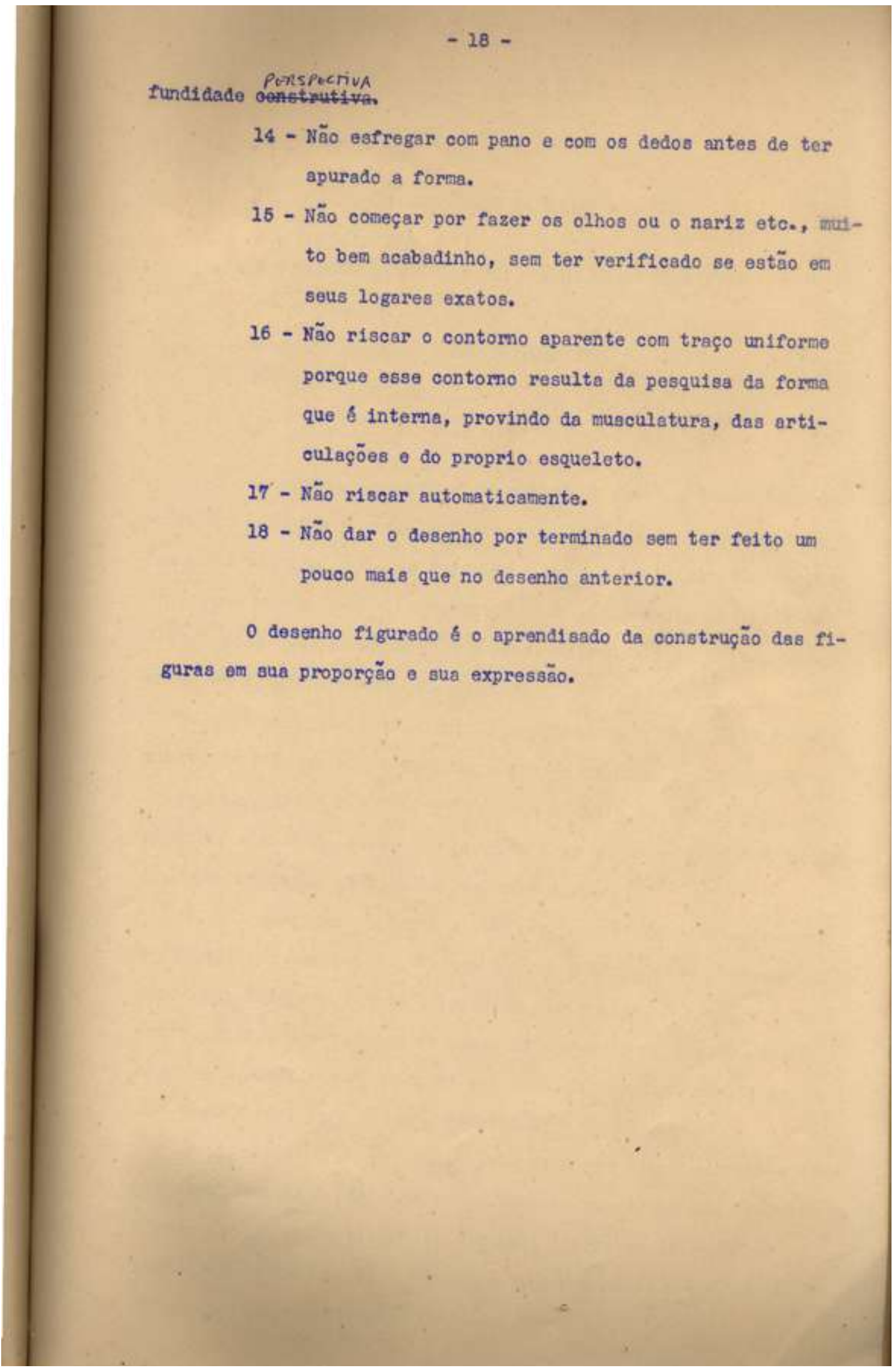




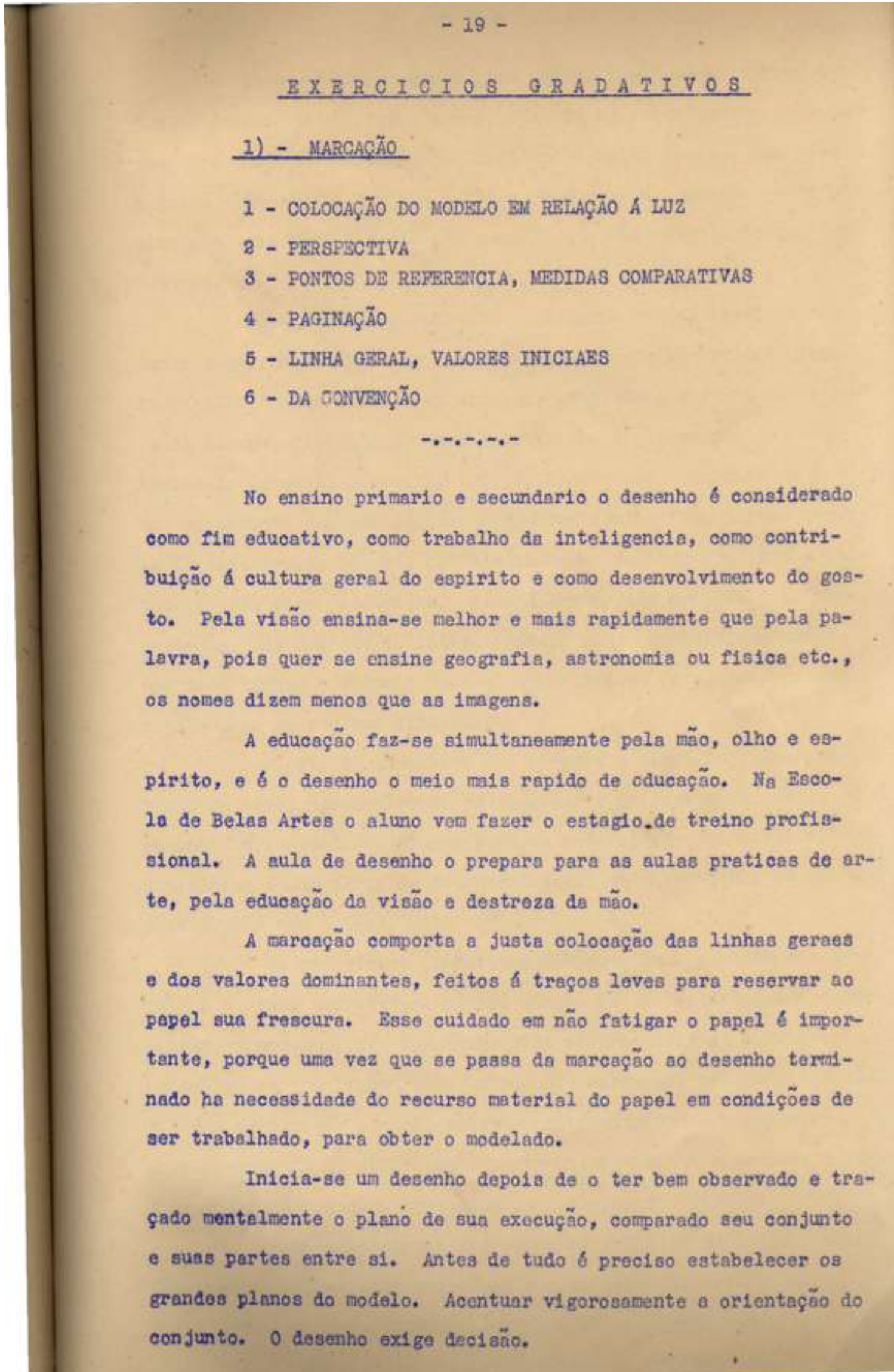


Zssa é a I1ção geral para todos, Ilção curta, porem de treino longo. Mente, olho e mão, devendo agir juntamente para conseguir a execugaäo do desenho, mas á mäo 6 muito lente a executar - que o olho já viu e o que a mente já entendeu. Outras vezes o olho não sabe vêr, a mente não percebe e a mão executa de qualquer maneira.

Portanto, 0 aprendiagdo do desenho requer treino constante e paciente. Para un bor resultado, contribue principalmente a aplicação do aluno, sel esforço, tenacidade e vontade, A aula de desenho figurado com nodelo estático 6 que se destina ao treino da mercação perfeita, 1sto é, construçäo, conjunto de formas exatamente em seus logares e sombras dominantes, porque na aula de modelo vivo, o modelo, mals ou menos se move $\theta$ sitera a at1tude de uma pose para outra. Alen disso a vida arrasts á Interpretaçäo. No đesenho do antigo (gesso) só a transposição exđ́ta das suas linhas a volumes para a superficie do papel, representa - estudo em si e a sua finalidade.

A aula de desenho é que prepara o aluno éa aulas pratices de arte, desenvolvendo as tecnicas e processos varios de desenho, orientendo os alunos para as necessidades do atelier, conduzindo-os á ume semie de descobertas que se encadelem o se contpletam umas nas outras.

$\mathrm{OB}$ exercicios gradativos compreendem uma ordem nos trabalhos a serem executados, näo 86 quanto ás difleulades que apreBentam os modelos, más nas extgencias progressivas da execução. Os trabalhos que tinham sido unicamente marcação, passam a ser estudados como claro escuro, relevo, particularidades e expressão. Como progressäo de dificuldade os trabalhos passam de cabeça e extremidades, A busto, torço, estatus a grupos de estatuas. Propositadanente até agora só fale1 de culdado, exatidẽo, paciencia, esforço e atençaõ e nada disse de arte e belesa. Para a cadelra de desenho do 12 ano, 1 sao pareceria sem proposito. Balei nas qualidades que săo susceptivels de seren ensingdas e 
săo as que ma1s Interessam o professor, Bssas mosines qualj הades não conferem aos trabalhos do oxtreantes valor artistico, mas săo qualidades bas1eas de eduoaçăo tradiclonal que todo aluno deve receber mesmo aqueles que săb atraicios mals espeololmente pelas novas tendenolas antistioss ou pelo espetroulo da vids que os cerca. Que nenhum aluno tema dimimin suas faculdades pelo estudo aprofindado o mimuoloso, Quanto maíor fôr sua oduoaçăo n'esse sentido, tanto malor será o poder de sua memorla, $\mathrm{d}_{\mathrm{Q}} \mathrm{g} \mathrm{f}^{6} \mathrm{r}-\mathrm{m}$ mas precisas a das proporçọes exátas, das noçöes controladas, das possib111dades e impossibilidades da netureza.

\section{COLOCACZO DO MODELO BM RETACZO \& LUZ}

A bôa colooaçăo do modelo em relação á luz, á a liఢ̧ăo 1njo1al.

Bt preo1so escolher o melhor efelto de luz e sombra, que melhor ponha em renloe a belesa do modelo, $\theta$ que estabeles ga pontos de roferenola que sirvam de base á comparaçäo do des senho com o modelo. Dopois, deve-se trater do ponto de vista, 1sto $\delta$, da colocação do observador. Não se p6de escolthor um loger qualquer para fazer um desenho, ó preciso que c modejo flque dentro do cone VIsual. Et preolso saber vêp e saber oo mo se vê. O olho pర́do ser comparado \&́ uma camara fotografloa. Adiante uma lente que projóta a Imagem, atraz a retina que a recebe. Os raios Iuminosos que pirtom do todos os pontos do objéto oonvorgem ao mesmo ponto da lente ocular onde se oruzem, projetando na retina a Imagem fnvertida, A rasäo da 1magem ser Invertida 6 porque ao se oruzarem os raios no centro 6 tioo, o que estava eir olma passou para batxo. Bssa lmagem Invertida restabelecemos t verdadelra pos1çäo por raciocinio instintivo. (Desenho $\mathrm{n}^{2}$ 1) A perspectiva of alentiflomente esso mesmo ree oloolnio. 


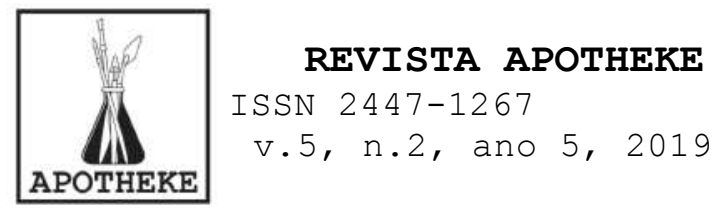

\section{BIBLIOGRAFIA}

BARBOSA, Ana Mae. Arte-Educação no Brasil: das origens ao modernismo. São Paulo: Editora Perspectiva, 1978.

BARBOSA, Ana Mae. Redesenhando o desenho: educadores, política e história. São Paulo: Editora Cortez, 2015.

EDWARDS, Betty. Drawing on the Right Side of the Brain Workbook. 1998, Penguin Putnam.

GOLOMB, Claire. The Child's creation of a Pictorial World. Berkeley, Los Angeles, Oxford. University of California Press, 1992, 353 pgs.

LUQUET, Georges-Henri. Les dessins d'un enfant (Children's Drawings). Paris, Librairie Félix Alcan, 1913.

MILANEZ, Carolina Gonçalves. Ensino da Arte e do Design em uma escola municipal de São Paulo. Universidade Anhembi Morumbi, Programa de Arte. Design e Tecnologia, 2016.

REBOUÇAS, André. Diário e Notas Autobiográficas. Coleção Documentos Brasileiros dirigida por Gilberto Freyre. Livraria José Olympio Editora, Rio, pág. 395 a 397, 1938.

The Notebooks of Leonardo da Vinci compiled and edited from the original manuscripts by Jean Paul Richter. New York: Dover Publications, 1970 .

VARTULI, MAximilian de Aguiar. 0 design do desenho: análise de ferramentas de desenho digital no projeto de produto. Mestrado Acadêmico em Design UDESC /CEART, 2016 pag 24.

SANOVICZ, Fernanda. Desenhos de Abrahão Sanovicz. São Paulo: SESC, 2016.

Endereço eletrônico do lattes:

http://lattes.cnpq.br/1650414096296319

Anna Mae Barbosa possui graduação em Direito - Universidade Federal de Pernambuco (1960), mestrado em Art Education - Southern Connecticut State College (1974) e doutorado em Humanistic Education - Boston University (1978). Atualmente é professora titular aposentada da Universidade de São Paulo e professora da Universidade Anhembi Morumbi. Tem experiência na área de Artes, com ênfase em Arte/Educação, atuando principalmente nos seguintes temas: Ensino da Arte e contextos metodológicos, História do Ensino da Arte e do Desenho , Ensino do Design, Administração de Arte, Interculturalidade, Pedagogia Visual, Estudos de Museus de Arte, Mediação Cultural e Estudos Visuais.

Recebido em 02 de agosto de 2019. Aceito em 19 de agosto de 2019. 
\begin{tabular}{|l|} 
REVISTA APOTHEKE \\
ISSN 2447-1267 \\
V.5, n.2, ano 5, 2019
\end{tabular}

Orcid: https://orcid.org/0000-0002-4966-2043 